\title{
Income-related inequalities in chronic conditions, physical functioning and psychological distress among older people in Australia: cross-sectional findings from the 45 and up study
}

\author{
Rosemary J Korda ${ }^{*}$, Ellie Paige ${ }^{1}$, Vasoontara Yiengprugsawan ${ }^{1}$, Isabel Latz ${ }^{2}$ and Sharon Friel ${ }^{1}$
}

\begin{abstract}
Background: The burden of chronic disease continues to rise as populations age. There is relatively little published on the socioeconomic distribution of this burden in older people. This study quantifies absolute and relative income-related inequalities in prevalence of chronic diseases, severe physical functioning limitation and high psychological distress in mid-age and older people in Australia.
\end{abstract}

Methods: Cross-sectional study of 208,450 participants in the 45 and Up Study, a population-based cohort of men and women aged 45-106 years from New South Wales, Australia. Chronic conditions included self-reported heart disease, diabetes, Parkinson's disease, cancer and osteoarthritis; physical functioning limitation (severe/not) was measured using Medical Outcomes Study measures and psychological distress (high/not) using the Kessler Psychological Distress Scale. For each outcome, prevalence was estimated in relation to annual household income (6 categories). Prevalence differences (PDs) and ratios (PRs) were generated, comparing the lowest income category $(<\$ 20,000)$ to the highest $(\geq \$ 70,000)$, using Poisson regression with robust standard errors, weighted for age, sex and region of residence. Analyses were stratified by age group (45-64, 65-79 and $\geq 80$ years) and sex and adjusted for age and country of birth.

Results: With few exceptions, there were income gradients in the prevalence of chronic conditions among all age-sex groups, with prevalence decreasing with increasing income. Of the chronic diseases, PDs were highest for diabetes (ranging between 5.69\% and 10.36\% across age-sex groups) and in women, also for osteoarthritis (5.72\% to 8.14\%); PRs were highest for osteoarthritis in men aged 45-64 years (4.01), otherwise they were highest for diabetes (1.78 to 3.43). Inequalities were very high for both physical functioning limitation and psychological distress, particularly among those aged 45-64 (PDs between 18.67\% and 29.23\% and PRs between 4.63 and 16.51). Absolute and relative inequalities tended to decrease with age, but remained relatively high for diabetes and physical functioning in the elderly ( $\geq 80$ years).

Conclusions: Significant inequalities in the prevalence of chronic conditions, physical functioning and psychological distress persist into old age. The additional health burden placed on those who are already disadvantaged is likely to become an increasingly important issue in an ageing population.

\footnotetext{
* Correspondence: Rosemary.Korda@anu.edu.au

${ }^{1}$ National Centre for Epidemiology and Population Health, Australian National University, Canberra ACT 0200, Australia

Full list of author information is available at the end of the article
} 


\section{Background}

Chronic conditions account for the majority of the disease burden worldwide and this burden continues to rise, principally due to population ageing [1,2]. In Australia, chronic diseases make up around $80 \%$ of the total burden of disease $[1,3]$. As the proportion of people aged over the age of 65 years in this country is estimated to rise-from 13\% to $23-25 \%$ by 2056 , with the proportion of those 85 years and over rising from $1.6 \%$ to $4.9-7.3 \%$ [4] - the total chronic disease burden and associated functional limitations is expected to increase substantially.

A particular challenge of chronic disease in an ageing population is not just the total burden, but its socioeconomic distribution. It is well established that people who are socioeconomically disadvantaged are more likely to develop chronic disease than those who are more advantaged; they are also more likely to be economically vulnerable to the consequences. The economic difficulties arise not just through loss of income, which mainly affects working-age adults, but through direct costs associated with the illness, including out-of-pocket medical expenses and transport and carer costs, further compounding socioeconomic disadvantage [5-7]. Although there is some evidence that inequalities may diminish in older people, [8-11] even relatively small inequalities in the older population may increasingly become a health and social policy issue as the population ages, given the high prevalence of chronic disease and associated functional limitations in older people [3].

With rapid population ageing, knowledge of incomerelated inequalities in chronic disease and associated physical and mental health problems in later life will be important for designing appropriate health and welfare programs. Yet, while many studies on socioeconomic inequalities in the prevalence of chronic conditions include older people, data are usually aggregated for these older participants (often $>65$ years) e.g. [12-15], (with some exceptions, e.g. $[9,16,17])$, and there is very limited evidence of inequalities specifically among the oldest old ( $\geq 80$ years) $[9,18]$. Further, relatively few studies present data on absolute inequalities, and in Australia, inequalities are often reported in relation to area-based measures of disadvantage, rather than at the individual or household level (e.g. [12]).

The aim of this paper is to quantify absolute and relative income-related inequalities in chronic diseases, physical functioning and psychological distress in mid-age and older Australians, using large-scale population-based study data that includes a large sample of people aged 80 years and over.

\section{Methods}

\section{Participants}

We used data from the 45 and Up Study, a cohort study involving over 250,000 men and women aged 45 and over from New South Wales (NSW), Australia; at the time of our study, we had data available on 266,848 participants. Participants in the Study were randomly sampled from the database of Medicare Australia, with over-sampling, by a factor of two, of individuals aged 80 years and over and people resident in rural areas. Around $10 \%$ of the entire NSW population aged 45 and over were included in the sample. Participants joined the Study by completing a baseline postal questionnaire, between January 2006 and March 2009. Further details of the Study are described in a separate publication [19], and questionnaires can be viewed at http://www.45andup.org.au.

\section{Study variables \\ Income}

Participants were asked about their annual household income before tax from all sources, (including benefits, pensions and superannuation). Response options included eight income brackets, from "less than $\$ 5,000$ per year" to " $\$ 70,000$ or more per year"; the three lowest income brackets (less than $\$ 5,000, \$ 5,000-\$ 9,999$ and $\$ 10,000-\$ 19,999$ per year) were combined for the analysis (see Table 1).

\section{Health outcomes}

The 45 and Up survey includes variables on a large range of current and past health conditions. For this study we only examined variables that measured the presence of current chronic health conditions - heart disease, diabetes,

Table 1 Number and percentage of males and females in each age group, by annual household income category

\begin{tabular}{|c|c|c|c|c|c|c|}
\hline & \multicolumn{6}{|c|}{ Age group (years) } \\
\hline & \multicolumn{2}{|c|}{$45-64$} & \multicolumn{2}{|c|}{$65-79$} & \multicolumn{2}{|c|}{$\geq 80$} \\
\hline & $n$ & $\%$ & $n$ & $\%$ & $n$ & $\%$ \\
\hline \multicolumn{7}{|l|}{ MALES } \\
\hline$<\$ 20 \mathrm{~K}$ & 6,838 & 11.1 & 11,249 & 35.5 & 4,933 & 47.4 \\
\hline$\$ 20-<30 \mathrm{~K}$ & 4,116 & 6.7 & 6,095 & 19.2 & 2,113 & 20.3 \\
\hline$\$ 30-<40 \mathrm{k}$ & 4,955 & 8.1 & 4,280 & 13.5 & 1,077 & 10.3 \\
\hline$\$ 40-<50 \mathrm{~K}$ & 5,891 & 9.6 & 3,041 & 9.6 & 714 & 6.9 \\
\hline$\$ 50-<70 \mathrm{~K}$ & 10,228 & 16.7 & 3,025 & 9.5 & 705 & 6.8 \\
\hline$\geq \$ 70 \mathrm{~K}$ & 29,272 & 47.8 & 4,040 & 12.7 & 876 & 8.4 \\
\hline Total & 61,300 & 100.0 & 31,730 & 100.0 & 10,418 & 100.0 \\
\hline \multicolumn{7}{|l|}{ FEMALES } \\
\hline$<\$ 20 \mathrm{~K}$ & 11,962 & 16.5 & 12,275 & 50.0 & 5,108 & 64.4 \\
\hline$\$ 20-<30 \mathrm{~K}$ & 7,335 & 10.1 & 4,613 & 18.7 & 1,236 & 15.6 \\
\hline$\$ 30-<40 k$ & 7,438 & 10.3 & 2,734 & 11.1 & 567 & 7.1 \\
\hline$\$ 40-<50 \mathrm{~K}$ & 7,412 & 10.3 & 1,803 & 7.3 & 358 & 4.5 \\
\hline$\$ 50-<70 \mathrm{~K}$ & 11,764 & 16.3 & 1,674 & 6.8 & 355 & 4.5 \\
\hline$\geq \$ 70 \mathrm{~K}$ & 26,417 & 36.5 & 1,639 & 6.6 & 312 & 3.9 \\
\hline Total & 72,328 & 100.0 & 24,738 & 100.0 & 7,936 & 100.0 \\
\hline
\end{tabular}


Parkinson's disease, cancer and osteoarthritis-and two outcomes commonly associated with chronic disease-physical functioning limitation and psychological distress [20-25]. Presence of heart disease, diabetes and Parkinson's disease was determined by asking the participant to indicate if 'a doctor ever told you that you have [that condition]'. Presence of osteoarthritis and cancer were determined by asking participants if 'in the last month have you been treated for [that condition]'. Physical functioning was assessed using the Medical Outcomes Study physical functioning activity items, which are equivalent to items from the physical functioning scale of the SF-36 health survey [26]. The scale assesses functional capacity by inquiring about an individual's ability to perform a range of moderate and vigorous physical tasks as well as everyday activities. The total MOSPF score ranges from 0 to 100 , and, as defined in previous studies [25,27], scores were categorised as severe physical functional limitation $(<60)$ or not $(\geq 60)$. Psychological distress was determined using the Kessler Psychological Distress Scale (K10) [28]. All items on the K10 begin with the phrase 'during the past 4 weeks, about how often did you feel (...)' followed by the description of an emotional state, such as: 'tired out for no good reason?' All answer options were based on a 5-point scale ('none of the time' (1), through to, 'all of the time' (5)). The K10 score has a range from 10 (no distress) to 50 (high distress) and, consistent with previous studies [25,29], scores of 22 and above were considered indicative of high levels of psychological distress.

\section{Statistical methods}

We calculated the prevalence of chronic conditions in each income category, separately by age group (45-64, 65-79 and $\geq 80$ years) and sex. We then used Poisson regression with robust variance estimation [30] to estimate prevalence differences (PDs, measures of absolute inequality) and prevalence ratios (PRs, measures of relative inequality), comparing prevalence in the lowest income category $(<\$ 20,000)$ to that in the highest $(\geq \$ 70,000)$. Analyses were weighted for age, sex and region of residence (major city, rural, remote) using data from the 2006 Australian census [31] and adjusted for age (5-year age bands) and country of birth (categorised as Australia/New Zealand; Europe/North America; Asia; Africa/Middle East; other). Model fit was tested using residual plots and deviance and Pearson goodness-of-fit tests, which all confirmed appropriateness of fit of the Poisson model, in all analyses.

We also performed a sensitivity analysis to explore the magnitude and direction of any potential bias in the inequality estimates due to the exclusion of participants with missing income data. We did this by estimating PRs in the sample using area-level socioeconomic status (SES) as the SES measure $(0.03 \%$ missing), comparing PRs in the full sample with those for whom income data were missing. Area-level SES was based on the Socio-Economic Indexes for Areas (SEIFA) Index of Relative Socioeconomic Disadvantage (IRSD) [32] derived from postcode of residence, and categorised into quintiles using cut-off scores from the 2006 Australian census. Analyses were carried out using Stata Version 13.1.

Ethics approval for this project was obtained from the NSW Population and Health Services Research Ethics Committee and the Australian National University Human Research Ethics Committee.

\section{Results}

After excluding participants with missing data on age $(\mathrm{n}=$ $752(0.3 \%))$ or household income $(n=57,646(21.6 \%))$, 208,450 participants $(78 \%)$ were included in the analysis. Those most likely to have missing income data were female, older, of lower education and in poor health $(\mathrm{p}<.001$ for all associations). The income profile of the final sample, by age and sex, is shown in Table 1. Household income varied by age, with the proportion of the high-income households decreasing, and low-income households increasing, with increasing age $(\mathrm{p}<.001$ for both males and females).

The prevalence of chronic conditions, severe physical functioning limitation and high psychological distress in each income category are shown separately by age group in Figures 1 (males) and 2 (females). Mostly there were clear socioeconomic gradients, with prevalence decreasing with increasing household income, the main exception being heart disease in men aged $\geq 80$ years, where there was a reverse gradient.

Adjusted prevalence differences and prevalence ratios, comparing the lowest and highest household income groups, are shown in Tables 2 (males) and 3 (females). Although heart disease was the most prevalent chronic disease in males, absolute inequalities (PDs) were highest for diabetes, ranging from 7.16\% (95\% CI: 4.96-9.36\%) in those aged $\geq 80$ years to $10.36 \%(9.33-11.38 \%)$ in those aged 45-64 years. Relative inequalities (PRs) were also highest for diabetes in males aged 65-79 $(\mathrm{PR}=1.98$ $(1.77-2.21))$ and $\geq 80$ years $(\mathrm{PR}=1.78(1.43-2.21))$, but in, males aged 45-64 years, relative inequality was highest for osteoarthritis $(\mathrm{PR}=4.01 \quad(3.50-4.50))$. For females, osteoarthritis was the most prevalent chronic disease (along with heart disease in those aged $\geq 80$ years), with PDs also highest for this disease and for diabetes (with PDs of between 6 and 10\% across all age groups for both diseases). Relative inequalities for females were also highest for diabetes in all age groups, ranging from 1.86 (1.21-2.84) in women aged over 80 years to 3.43 (2.624.48) in women aged 65-79. The PDs and PRs for physical functioning limitation and psychological distress were very high, particularly in those aged 45-64, with PDs of $29.23 \%(27.86-30.61 \%)$ in males and $22.91 \%$ (21.85- 

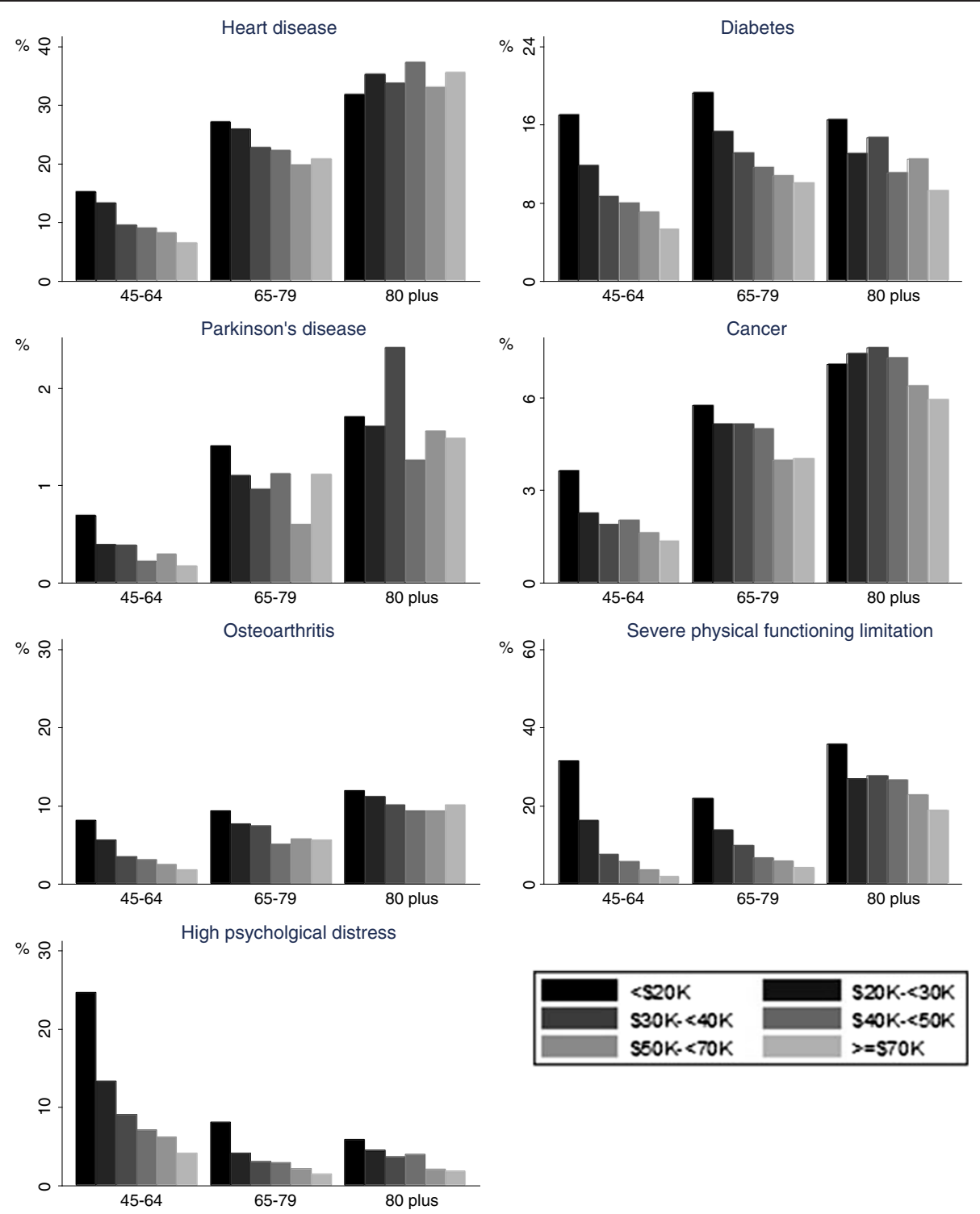

Figure 1 Prevalence of chronic diseases, severe physical functioning limitation and high psychological distress by annual household income category, males. Notes: 1. Different scale used for different outcomes. 2. Severe physical functioning limitation is a score $<60$ on the MOS-PF 3. High psychological distress is a Kessler Psychological Distress Scale score of $\geq 22$.

23.98\%) in females for severe physical functioning limitation (respective PRs of 16.51 (14.90-18.29) and 8.15 (7.46-8.90)); and PDs of $24.19 \%$ (22.81-25.57\%) in males and $18.67 \%(17.61-19.73 \%)$ in females for high psychological distress (respective PRs of 7.15 (6.61-7.73) and 4.63 (4.31-4.97)).

Broad comparisons of inequalities across age groups show that, although prevalence of chronic disease and severe physical functioning limitation (but not high psychological distress) increased with age, in men both absolute (PDs) and relative inequalities (PRs) were highest in the youngest age group (45-64); in women absolute inequalities were highest in the two youngest age groups
(45-64 and 65-79), and relative inequalities (PRs) were, with the exception of diabetes, always highest in the youngest age group (45-64).

The sensitivity analysis showed there was no change in the direction, and little difference in magnitude, of the PRs based on area-disadvantage among the sample with income missing compared to the full sample (results available on request).

\section{Discussion}

Substantial socioeconomic inequalities in chronic disease, physical functioning and psychological distress are evident in mid-age and older adults in Australia, with 

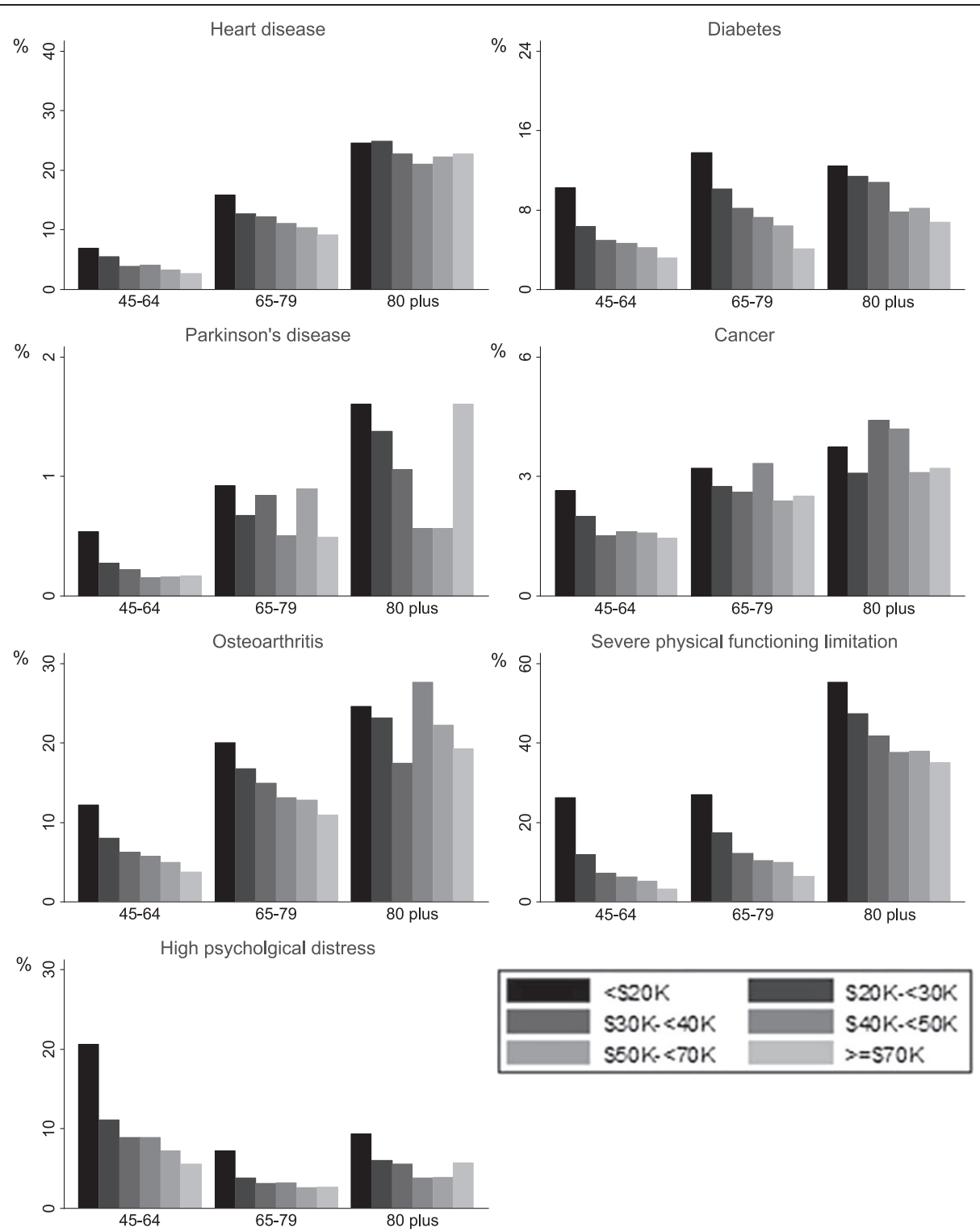

Figure 2 Prevalence of chronic diseases, severe physical functioning limitation and high psychological distress by annual household income category, females. Notes: 1. Different scale used for different outcomes. 2. Severe physical functioning limitation is a score $<60$ on the MOS-PF 3. High psychological distress is a Kessler Psychological Distress Scale score of $\geq 22$.

the prevalence of these conditions generally increasing with decreasing household income. Our findings provide empirical evidence of income-related inequalities not just in working-age individuals, but also older people, including the oldest old, where the overall burden of chronic disease is very high. The PRs reported in this study are greater than those seen for many other chronic disease risk factors, bearing in mind socioeconomic inequalities are, to some extent, likely to reflect the inequalities in prevalence of these other risk factors (e.g. smoking) [33]. The particularly high levels of diabetes, osteoarthritis, physical functioning limitations and psychological distress amongst people in lower income households is especially concerning, both from an individual and population perspective, given the high associated health care needs and costs [34].

Our results are generally consistent with those of other Australian and international studies of mid-age and older age people ( $>65$ years), which report significant socioeconomic inequalities in the prevalence of chronic diseases, physical functional limitations and mental health problems, across different measures of SES, although not necessarily for all health conditions [7-10,12-18,35-41]; an earlier Australian report actually showed reverse gradients in cancer [13], a pattern also reported in older-age Europeans (aged 60-79 years) [16]. Our study adds to 
Table 2 Prevalence (\%) of chronic conditions, severe physical functioning limitation and high psychological distress in the total group and the lowest and highest income groups, and prevalence differences (PD) and prevalence ratios (PR) (with $95 \%$ confidence intervals), amongst males, by age group

\begin{tabular}{|c|c|c|c|}
\hline & \multicolumn{3}{|c|}{ Age group (years) } \\
\hline & $45-64$ & $65-79$ & $\geq 80$ \\
\hline \multicolumn{4}{|l|}{ Heart disease } \\
\hline Total & $8.52(8.28-8.76)$ & $24.43(23.91-24.96)$ & $33.54(32.63-34.45)$ \\
\hline Low income & $13.24(12.39-14.08)$ & $26.47(25.56-27.38)$ & $31.99(30.67-33.31)$ \\
\hline High income & $7.14(6.80-7.48)$ & $22.58(21.13-24.03)$ & $35.00(31.84-38.16)$ \\
\hline PD & $6.10(5.17-7.02)$ & $3.89(2.16-5.62)$ & $-3.01(-6.44-0.42)$ \\
\hline$P R$ & $1.85(1.71-2.01)$ & $1.17(1.09-1.26)$ & $0.91(0.83-1.01)$ \\
\hline \multicolumn{4}{|l|}{ Diabetes } \\
\hline Total & $7.86(7.63-8.10)$ & $14.92(14.48-15.35)$ & $14.28(13.61-14.96)$ \\
\hline Low income & $16.02(15.06-16.98)$ & $19.33(18.50-20.16)$ & $16.40(15.36-17.44)$ \\
\hline High income & $5.66(5.36-5.97)$ & 9.77 (8.78-10.77) & $9.24(7.31-11.17)$ \\
\hline PD & $10.36(9.33-11.38)$ & $9.56(8.25-10.87)$ & $7.16(4.96-9.36)$ \\
\hline$P R$ & $2.83(2.61-3.07)$ & $1.98(1.77-2.21)$ & $1.78(1.43-2.21)$ \\
\hline \multicolumn{4}{|l|}{ Cancer } \\
\hline Total & $1.75(1.64-1.86)$ & $4.92(4.66-5.18)$ & $7.01(6.52-7.51)$ \\
\hline Low income & $3.23(2.77-3.68)$ & $5.49(5.02-5.96)$ & $7.06(6.33-7.78)$ \\
\hline High income & $1.45(1.29-1.60)$ & $4.08(3.40-4.76)$ & $5.78(4.24-7.31)$ \\
\hline PD & $1.78(1.29-2.26)$ & $1.41(0.58-2.24)$ & $1.28(0.42-2.98)$ \\
\hline$P R$ & $2.23(1.86-2.67)$ & $1.35(1.12-1.62)$ & $1.22(0.92-1.62)$ \\
\hline \multicolumn{4}{|l|}{ Osteoarthritis } \\
\hline Total & $2.91(2.76-3.05)$ & $7.45(7.13-7.77)$ & $11.12(10.51-11.73)$ \\
\hline Low income & $7.42(6.73-8.12)$ & $9.16(8.56-9.76)$ & $11.95(11.04-12.87)$ \\
\hline High income & $1.85(1.68-2.03)$ & $5.84(5.04-6.65)$ & $10.24(8.20-12.27)$ \\
\hline PD & $5.57(4.85-6.29)$ & $3.32(2.30-4.34)$ & $1.72(0.52-3.96)$ \\
\hline$P R$ & 4.01 (3.50-4.59) & $1.57(1.34-1.83)$ & $1.17(0.94-1.45)$ \\
\hline \multicolumn{4}{|c|}{ Parkinson's disease } \\
\hline Total & $0.28(0.23-0.33)$ & 1.19 (1.05-1.32) & $1.70(1.45-1.95)$ \\
\hline Low income & $0.60(0.39-0.80)$ & $1.41(1.16-1.65)$ & $1.72(1.35-2.09)$ \\
\hline High income & $0.17(0.12-0.23)$ & $1.33(0.91-1.74)$ & $1.48(0.68-2.28)$ \\
\hline PD & $0.43(0.21-0.64)$ & $0.08(-0.40-0.57)$ & $0.24(-0.64-1.12)$ \\
\hline$P R$ & $3.45(2.14-5.55)$ & $1.06(0.74-1.52)$ & $1.16(0.65-2.08)$ \\
\hline \multicolumn{4}{|c|}{ Severe physical functioning limitation } \\
\hline Total & $6.42(6.22-6.62)$ & $12.69(12.27-13.11)$ & $29.86(28.88-30.83)$ \\
\hline Low income & $31.12(29.76-32.48)$ & $21.46(20.52-22.4)$ & $35.42(33.88-36.95)$ \\
\hline High income & $1.89(1.71-2.06)$ & $4.36(3.64-5.07)$ & $18.89(16.12-21.66)$ \\
\hline PD & $29.23(27.86-30.61)$ & $17.10(15.91-18.30)$ & $16.53(13.35-19.70)$ \\
\hline$P R$ & $16.51(14.9-18.29)$ & $4.93(4.15-5.85)$ & $1.87(1.61-2.18)$ \\
\hline \multicolumn{4}{|c|}{ High psychological distress } \\
\hline Total & $7.68(7.45-7.91)$ & $4.61(4.34-4.88)$ & $4.61(4.15-5.08)$ \\
\hline Low income & $28.13(26.77-29.48)$ & $8.58(7.92-9.24)$ & $5.85(5.07-6.63)$ \\
\hline High income & $3.94(3.70-4.18)$ & $1.36(0.97-1.75)$ & $1.92(0.92-2.93)$ \\
\hline PD & $24.19(22.81-25.57)$ & $7.21(6.44-7.98)$ & $3.93(2.66-5.20)$ \\
\hline$P R$ & 7.15 (6.61-7.73) & $6.29(4.68-8.46)$ & 3.04 (1.78-5.22) \\
\hline
\end{tabular}

Notes: 1. Severe physical functioning limitation is a score $<60$ on the MOS-PF 2. High psychological distress is a Kessler Psychological Distress Scale score of $\geq 22.3$. Analyses are weighted for age group, sex and region, and adjusted for age (5-year age groups) and country of birth. 
Table 3 Prevalence (\%) of chronic conditions, severe physical functioning limitation and high psychological distress in the total group and the lowest and highest income groups, and prevalence differences (PD) and prevalence ratios (PR) (with $95 \%$ confidence intervals), amongst females, by age group

\begin{tabular}{|c|c|c|c|}
\hline & \multicolumn{3}{|c|}{ Age group (years) } \\
\hline & $45-64$ & $65-79$ & $\geq 80$ \\
\hline \multicolumn{4}{|l|}{ Heart disease } \\
\hline Total & $3.83(3.68-3.99)$ & 13.69 (13.20-14.18) & $24.30(23.35-25.26)$ \\
\hline Low income & $5.85(5.38-6.32)$ & $15.42(14.69-16.15)$ & $24.77(23.56-25.97)$ \\
\hline High income & $2.95(2.70-3.19)$ & $9.74(8.09-11.40)$ & $22.90(18.17-27.63)$ \\
\hline PD & $2.90(2.37-3.44)$ & $5.67(3.86-7.49)$ & $1.87(-3.01-6.75)$ \\
\hline$P R$ & $1.99(1.76-2.23)$ & $1.58(1.33-1.89)$ & $1.08(0.87-1.34)$ \\
\hline \multicolumn{4}{|l|}{ Diabetes } \\
\hline Total & $5.15(4.97-5.34)$ & 10.78 (10.34-11.22) & $11.44(10.73-12.14)$ \\
\hline Low income & $9.68(9.07-10.29)$ & 13.58 (12.88-14.27) & $12.33(11.42-13.24)$ \\
\hline High income & $3.50(3.24-3.77)$ & $3.96(2.92-5.01)$ & $6.64(3.86-9.41)$ \\
\hline PD & $6.18(5.50-6.85)$ & $9.61(8.35-10.87)$ & $5.69(2.77-8.62)$ \\
\hline$P R$ & $2.76(2.50-3.05)$ & $3.43(2.62-4.48)$ & $1.86(1.21-2.84)$ \\
\hline \multicolumn{4}{|l|}{ Cancer } \\
\hline Total & $1.70(1.59-1.81)$ & $2.98(2.73-3.22)$ & $3.72(3.30-4.15)$ \\
\hline Low income & $2.50(2.18-2.83)$ & $3.23(2.86-3.59)$ & $3.85(3.31-4.39)$ \\
\hline High income & $1.54(1.37-1.71)$ & $2.57(1.71-3.42)$ & $2.97(1.13-4.81)$ \\
\hline PD & $0.96(0.59-1.34)$ & $0.66(0.27-1.60)$ & $0.88(-1.04-2.80)$ \\
\hline$P R$ & $1.63(1.36-1.94)$ & $1.26(0.88-1.79)$ & $1.30(0.69-2.45)$ \\
\hline \multicolumn{4}{|l|}{ Osteoarthritis } \\
\hline Total & $6.07(5.88-6.27)$ & $17.29(16.75-17.83)$ & $23.78(22.83-24.73)$ \\
\hline Low income & $10.82(10.20-11.44)$ & 19.90 (19.09-20.72) & $24.76(23.55-25.96)$ \\
\hline High income & $4.23(3.94-4.52)$ & $11.76(9.97-13.55)$ & $19.04(14.65-23.42)$ \\
\hline PD & $6.59(5.89-7.29)$ & $8.14(6.17-10.12)$ & $5.72(1.17-10.27)$ \\
\hline$P R$ & $2.56(2.33-2.81)$ & $1.69(1.44-1.98)$ & $1.30(1.03-1.65)$ \\
\hline \multicolumn{4}{|c|}{ Parkinson's disease } \\
\hline Total & $0.22(0.19-0.26)$ & $0.86(0.73-1.00)$ & $1.42(1.16-1.68)$ \\
\hline Low income & $0.48(0.35-0.62)$ & $1.00(0.79-1.21)$ & $1.57(1.23-1.91)$ \\
\hline High income & $0.17(0.11-0.22)$ & $0.36(0.07-0.66)$ & $1.58(0.18-2.98)$ \\
\hline PD & $0.32(0.16-0.47)$ & $0.64(0.28-1.00)$ & $0.01(-1.45-1.43)$ \\
\hline$P R$ & $2.88(1.84-4.50)$ & $2.75(1.19-6.35)$ & $0.99(0.40-2.46)$ \\
\hline \multicolumn{4}{|c|}{ Severe physical functioning limitation } \\
\hline Total & $8.28(8.05-8.51)$ & $19.47(18.87-20.07)$ & $50.59(49.35-51.83)$ \\
\hline Low income & $26.12(25.09-27.14)$ & $26.52(25.52-27.52)$ & $54.84(53.27-56.42)$ \\
\hline High income & $3.20(2.96-3.45)$ & $7.50(5.93-9.06)$ & $36.53(30.51-42.55)$ \\
\hline PD & $22.91(21.85-23.98)$ & $19.02(17.15-20.89)$ & $18.31(12.08-24.55)$ \\
\hline$P R$ & $8.15(7.46-8.90)$ & $3.54(2.86-4.37)$ & $1.50(1.27-1.78)$ \\
\hline \multicolumn{4}{|c|}{ High psychological distress } \\
\hline Total & $9.35(9.11-9.59)$ & $5.30(4.95-5.66)$ & $7.99(7.27-8.71)$ \\
\hline Low income & $23.82(22.81-24.83)$ & $7.64(7.02-8.26)$ & $9.18(8.23-10.13)$ \\
\hline High income & $5.15(4.85-5.44)$ & $2.73(1.81-3.65)$ & $6.56(3.24-9.87)$ \\
\hline PD & $18.67(17.61-19.73)$ & $4.91(3.80-6.02)$ & $2.62(0.83-6.07)$ \\
\hline$P R$ & $4.63(4.31-4.97)$ & $2.80(1.98-3.96)$ & $1.40(0.84-2.35)$ \\
\hline
\end{tabular}

Notes: 1. Severe physical functioning limitation is a score $<60$ on the MOS-PF 2. High psychological distress is a Kessler Psychological Distress Scale score of $\geq 22.3$.

Analyses are weighted for age group, sex and region, and adjusted for age (5-year age groups) and country of birth. 
the limited empirical evidence, conducted in the 1990s, on inequalities in the oldest old ( $\geq 80$ years). A crosssectional study involving 11 European countries found income and educational inequalities in reductions in daily activities due to physical or mental health problems, and long-term disabilities, in the 60-69 and 7079 year age groups but, unlike our study, not in those aged $\geq 80$ years (except for disabilities in men $\geq 80$ years) [9]. In a Swedish study, clear occupational class inequalities in self-reported circulatory problems and "aches and pains", as well as measured lung function, were reported in people aged 77-98 years [18].

Of the chronic diseases examined in our study, absolute and relative inequalities were highest for diabetes and osteoarthritis. This contrasts to an earlier report of income-related relative inequalities in chronic disease in Australia (2001 data), where gradients in these diseases were not always evident (only for diabetes in females aged 25-64 and males aged $\geq 65$, and for arthritis in those aged 25-64 (absolute inequalities not reported)) [13]. However, our findings are similar to those from a large study of pooled national surveys (1990s) involving eight European countries, which also found relative inequalities were high for diabetes and arthritis (as well as stroke and diseases of the nervous system) [16]. More recent international studies (2004-2008) show modest absolute and relative income inequalities in diabetes in some countries, but not in others $[14,17,40]$. While difficult to make direct comparisons between studies, differences in findings are likely to reflect difference across time and place in underlying social conditions and risk factors, such as obesity, physical inactivity and smoking. With regard to the finding of large inequalities in physical functional limitations, this has been consistently reported among mid age and older people in previous studies $[9,15,17,35-37,39,41]$. Our finding of substantial inequalities in high psychological distress, particularly among younger people, is also consistent with the weight of evidence, showing higher prevalence of mental health problems among lower socioeconomic groups [42], although inequalities in older people have been less consistently reported $[17,35,43]$.

While we did not directly test if the extent of inequality in chronic conditions differed significantly across age groups, we found absolute and relative inequalities were for the most part smaller in the older adults. This is broadly consistent with the findings from other crosssectional studies, showing relative, but not necessarily absolute, inequalities tend to diminish with age $[9,16]$; and with longitudinal studies in Australia [10] and the U.S. [8], showing widening of absolute inequalities in physical impairment in mid-adult years, but narrowing in older ages. Nevertheless, at a population level, with the combination of high overall prevalence of chronic disease and high proportion of low-income households in the very old, the total excess burden associated with low income is likely to be substantial in this age group.

It was not the aim of this paper to determine causality between income and chronic disease, which is not possible with these cross-sectional data and with limited adjustment of covariates. Rather, by quantifying the extent of inequality in chronic conditions in different age groups we were able to show that the burden of disease is greater among individuals in lower income households, a finding which holds true even into older age, albeit to a relatively smaller extent. These findings are likely to reflect several factors, including inequalities in incidence (albeit not necessarily at older ages [44]), arising through multiple mechanisms [45]. Moreover, it is likely that the income gradients in these conditions to some extent reflect the known socioeconomic gradients in risk factors for chronic disease, including smoking, obesity and physical inactivity $[13,34]$, as well as other inequalities, such as use of health care e.g. [46-48]. The findings also reflect survival, as well as 'reverse causality'. In particular, the very high incomerelated inequalities seen in physical function in the 45-64 age-group in this study are likely to be explained at least in part by the fact that while socioeconomic disadvantage is a risk factor for poor health, poor health also affects income, particularly in people of working age [49]. The lower relative inequalities in older people may partly reflect the 'survivor effect', whereby the negative effect of low SES on health means those remaining in the cohort are not a random sample of the population but rather reflect those who are more likely to have survived the effect of low SES on premature mortality [11].

Strengths of this study include that it is an order of magnitude larger than previous national and international studies investigating the relationship of SES to health outcomes in mid-age and older people; and the oversampling of individuals aged over 80 years meant that we had the power to examine variations in outcomes in the very old, this increasingly important group as the population ages, yet one which is often excluded (or at best aggregated) in population health studies.

Limitations of this study include that it is based on selfreported health outcomes, and that the physical functional limitations and psychological distress measures may not necessarily reflect chronic conditions. Further, like many population-based cohort studies, the response rate was low $(\sim 18 \%)$. It was decided at study conception that the main concern was to obtain a large sample, with data across a wide variety of exposures rather than focusing on response rates. As such, while the sample was randomly drawn, it is unlikely to be representative of the general population and thus caution should be used when interpreting and generalising absolute prevalence estimates. However, representativeness is not necessary for reliable 
estimates of relative risks based on internal comparisons within study populations, and it has been shown that the relative measures estimated from non-representative studies are consistent with the relative measures estimated from representative studies [50,51]. As such, the relative inequality estimates, as measured in this study, are assumed to be valid and broadly generalisable, particularly if it can be assumed that the extent of errors in selfreporting do not differ by income or by selection into the study. Similarly, although inequality estimates may be biased due to the exclusion of those with missing income data, this is only likely to be the case if the strength of association between SES and health is different in those excluded, and the results of the sensitivity analysis suggested this was not the case.

\section{Conclusion}

There has been some uncertainty as to the magnitude of health inequality in older ages, and indeed whether the magnitude of inequality is meaningful. This study suggests it is, with significant inequalities in the prevalence of chronic conditions, severe physical limitations and high psychological distress evident among elderly people. The increased burden in these groups highlights the importance of considering the wider implications of inequalities in chronic conditions among these age groups, including the costs borne by individuals and households in managing chronic illness, and how this places further burden on those in the community who are already disadvantaged. The findings also pose the policy challenge of needing to prevent such inequalities in older years, which arguably manifest much earlier in peoples' lives. These health inequalities are likely to become an increasingly important economic and social issue in an ageing population.

\section{Competing interests}

The authors declare that they have no competing interests.

\section{Authors' contributions}

RK designed and coordinated the study, and drafted the manuscript. IL and EP carried out the statistical analysis and helped draft the manuscript. W and SF participated in the design of the study and helped draft the manuscript. All authors read and approved the final manuscript.

\section{Author details}

${ }^{1}$ National Centre for Epidemiology and Population Health, Australian National University, Canberra ACT 0200, Australia. ${ }^{2}$ School of Public Health, University of California, Los Angeles, USA.

Received: 28 June 2013 Accepted: 9 July 2014

Published: 22 July 2014

\section{References}

1. Beaglehole R, Bonita R, Horton R, Adams C, Alleyne G, Asaria P, Baugh V, Bekedam H, Billo N, Casswell S, Cecchini M, Colagiuri R, Colagiuri S, Collins T, Ebrahim S, Engelgau M, Galea G, Gaziano T, Geneau R, Haines A, Hospedales J, Jha P, Keeling A, Leeder S, Lincoln P, McKee M, Mackay J, Magnusson R, Moodie R, Mwatsama M, et al: Priority actions for the non-communicable disease crisis. Lancet 2011, 377(9775):1438-1447. PubMed PMID: 21474174. Epub 2011/04/09. eng.
2. Institute for Health Metrics and Evaluation: Seattle: IHME. The Global Burden of Disease: Generating Evidence, Guiding Policy; 2013.

3. Australian Institute of Health and Welfare: Australia's health 2012. Canberra: AlHW; 2012.

4. ABS: Population Projections, Australia, 2006-2101 (cat. no. 3222.0). Canberra: Australian Bureau of Statistics; 2008. Available from: http://www.abs.gov.au/ Ausstats/abs@.nsf/mf/3222.0.

5. WHO: Closing the gap in a generation: health equity through action on the social determinants of health. Geneva: The World Health Organization and Commission on Social Determinants of Health; 2008.

6. Jan S, Essue BM, Leeder SR: Falling through the cracks: the hidden economic burden of chronic illness and disability on Australian households. Med J Aust 2012, 196(1):29-31. PubMed PMID: 22256924. Epub 2012/01/20. eng.

7. Di Cesare M, Khang YH, Asaria P, Blakely T, Cowan MJ, Farzadfar F, Guerrero R, Ikeda N, Kyobutungi C, Msyamboza KP, Oum S, Lynch JW, Marmot MG, Ezzati M: Inequalities in non-communicable diseases and effective responses. Lancet 2013, 381(9866):585-597. PubMed PMID: 23410608. Epub 2013/02/16. eng.

8. Beckett M: Converging health inequalities in later life-an artifact of mortality selection? J Health Soc Behav 2000, 41(1):106-119. PubMed PMID: 10750325. Epub 2000/04/06. eng.

9. Huisman M, Kunst AE, Mackenbach JP: Socioeconomic inequalities in morbidity among the elderly; a European overview. Soc Sci Med 2003, 57(5):861-873. PubMed PMID: 12850111. Epub 2003/07/10. eng.

10. Mishra GD, Ball K, Dobson AJ, Byles JE: Do socioeconomic gradients in women's health widen over time and with age? Soc Sci Med 2004, 58(9):1585-1595. PubMed PMID: 14990361.

11. McMunn A, Nazroo J, Breeze E: Inequalities in health at older ages: a longitudinal investigation of the onset of illness and survival effects in England. Age Ageing 2009, 38(2):181-187. PubMed PMID: 19029098. Pubmed Central PMCID: 2724887. Epub 2008/11/26. eng.

12. Glover J, Hetzel D, Tennant S: The socioeconomic gradient and chronic illness and associated risk factors in Australia. Australia and New Zealand Health Policy 2004, 1(1):8.

13. Turrell G, Stanley L, de Looper M, Oldenburg B: Health Inequalities in Australia: morbidity, health behaviours, risk factors and health service use. Health inequalities monitoring series No. 2. AlHW cat. no. PHE 72. Brisbane and Canberra: Queensland University of Technology and the Australian Institute of Health and Welfare; 2006.

14. Savva GM, Maty SC, Setti A, Feeney J: Cognitive and physical health of the older populations of England, the United States, and Ireland: international comparability of the Irish Longitudinal Study on Ageing. J Am Geriatr Soc 2013, 61(Suppl 2):S291-S298. PubMed PMID: 23662721. Epub 2013/05/17. eng.

15. Tsimbos C: An assessment of socio-economic inequalities in health among elderly in Greece, Italy and Spain. Int J Public Health 2010, 55(1):5-15. PubMed PMID: 19806317. Epub 2009/10/07. eng.

16. Dalstra JA, Kunst AE, Borrell C, Breeze E, Cambois E, Costa G, Geurts JJ, Lahelma E, Van Oyen H, Rasmussen NK, Regidor E, Spadea T, Mackenbach JP: Socioeconomic differences in the prevalence of common chronic diseases: an overview of eight European countries. Int J Epidemiol 2005, 34(2):316-326. PubMed PMID: 15737978. Epub 2005/03/02. eng.

17. Lima-Costa MF, De Oliveira C, Macinko J, Marmot M: Socioeconomic inequalities in health in older adults in Brazil and England. Am J Public Health 2012, 102(8):1535-1541. PubMed PMID: 22698020. Pubmed Central PMCID: PMC3464850. Epub 2012/06/16. eng.

18. Rai D, Zitko P, Jones K, Lynch J, Araya R: Country- and individual-level socioeconomic determinants of depression: multilevel cross-national comparison. Br J Psychiatry 2013, 202(3):195-203. PubMed PMID: 23349294. Epub 2013/01/26. eng.

19. Banks E, Redman S, Jorm L, Armstrong B, Bauman A, Beard J, Beral V, Byles J, Corbett S, Cumming R, Harris M, Sitas F, Smith W, Taylor L, Wutzke S, Lujic S: Cohort profile: the 45 and up study. Int J Epidemiol 2008, 37(5):941-947. PubMed PMID: 17881411.

20. Holden L, Scuffham P, Hilton M, Vecchio N, Whiteford H: Psychological distress is associated with a range of high-priority health conditions affecting working Australians. Aust N Z J Public Health 2010, 34(3):304-310. PubMed PMID: 20618274. Epub 2010/07/14. eng.

21. Taylor A, Chittleborough C, Gill T, Winefield H, Koster C, Hornibrook L: Consensus statement on chronic disease and psychological distress. The 
Assessment of the Determinants and Epidemiology of Psychological Distress (ADEPD) study. Adelaide: Discipline of Psyhciatry, University of Adelaide; 2009. Available at: http://health.adelaide.edu.au/pros/docs/reports/ report_adepd_consensus_statement.pdf.

22. Boult C, Kane RL, Louis TA, Boult L, McCaffrey D: Chronic conditions that lead to functional limitation in the elderly. J Gerontol 1994, 49(1):M28-M36. PubMed PMID: 8282978. Epub 1994/01/01. eng.

23. Kempen Gl, Ormel J, Brilman El, Relyveld J: Adaptive responses among Dutch elderly: the impact of eight chronic medical conditions on healthrelated quality of life. Am J Public Health 1997, 87(1):38-44. PubMed PMID: 9065224. Pubmed Central PMCID: PMC1380762. Epub 1997/01/01. eng.

24. Chittleborough CR, Winefield H, Gill TK, Koster C, Taylor AW: Age differences in associations between psychological distress and chronic conditions. Int J Public Health 2011, 56(1):71-80. PubMed PMID: 20886258. Epub 2010/10/05. eng.

25. Byles JE, Robinson I, Banks E, Gibson R, Leigh L, Rodgers B, Curryer C, Jorm L: Psychological distress and comorbid physical conditions: disease or disability? Depress Anxiety 2013, PubMed PMID: 23922120. Epub 2013/08/08. Eng.

26. Ware JE: SF-36 ${ }^{\oplus}$ Health Survey Update. http://www.sf-36.org/tools/sf36. shtml Lincoln, Rl: Quality Metric; n.d. [cited 201218 Dec 2012]

27. Banks E, Jorm L, Rogers K, Clements M, Bauman A: Screen-time, obesity, ageing and disability: findings from 91266 participants in the 45 and Up Study. Public Health Nutr 2011, 14(1):34-43. PubMed PMID: 20409356. Epub 2010/04/23. eng.

28. Australian Institute of Health and Welfare: 4817.0.55.001 - Information Paper: Use of the Kessler Psychological Distress Scale in ABS Health Surveys, Australia, 2007-08. Canberra: AlHW; 2012. http://www.abs.gov.au/AUSSTATS/abs@.nsf/ Lookup/4817.0.55.001Main+Features12007-08?OpenDocument.

29. Banks E, Byles JE, Gibson RE, Rodgers B, Latz IK, Robinson IA, Williamson AB, Jorm LR: Is psychological distress in people living with cancer related to the fact of diagnosis, current treatment or level of disability? Findings from a large Australian study. Med J Aust 2010, 193(5 Suppl):S62-S67. PubMed PMID: 21542449. Epub 2011/05/06. eng.

30. Zou G: A modified poisson regression approach to prospective studies with binary data. Am J Epidemiol 2004, 159(7):702-706.

31. Australian Bureau of Statistics: 2006 Census Data Canberra: ABS; 2006. [updated 20 March 2014; cited 201418 June]. Available from: http://abs.gov. au/websitedbs/censushome.nsf/home/historicaldata2006.

32. Australian Bureau of Statistics: 2039.0 - Information Paper: An Introduction to Socio-Economic Indexes for Areas (SEIFA), 20062008 [22/12/2010]. Available from: http://www.abs.gov.au/ausstats/abs@.nsf/mf/2039.0/.

33. Stringhini S, Dugravot A, Shipley M, Goldberg M, Zins M, Kivimaki M, Marmot M, Sabia S, Singh-Manoux A: Health behaviours, socioeconomic status, and mortality: further analyses of the British Whitehall II and the French GAZEL prospective cohorts. PLoS Med 2011, 8(2):e1000419. PubMed PMID: 21364974. Pubmed Central PMCID: PMC3043001. Epub 2011/03/03. eng.

34. Australian Institute of Health and Welfare: Australia's health 2012. Australia's health no. 13. Cat. no. AUS 156. Canberra: AlHW; 2012.

35. Breeze E, Fletcher AE, Leon DA, Marmot MG, Clarke RJ, Shipley MJ: Do socioeconomic disadvantages persist into old age? Self-reported morbidity in a 29-year follow-up of the Whitehall Study. Am J Public Health 2001, 91(2):277-283. PubMed PMID: 11211638. Epub 2001/02/24. eng.

36. Koster A, Bosma H, van Broese Groenou Ml, Kempen Gl, Penninx BW, van Eijk JT, Deeg DJ: Explanations of socioeconomic differences in changes in physical function in older adults: results from the Longitudinal Aging Study Amsterdam. BMC Public Health 2006, 6:244. PubMed PMID: 17022819. Pubmed Central PMCID: PMC1621070. Epub 2006/10/07. eng.

37. Sulander T, Martelin T, Sainio P, Rahkonen O, Nissinen A, Uutela A: Trends and educational disparities in functional capacity among people aged 65-84 years. Int J Epidemiol 2006, 35(5):1255-1261. PubMed PMID: 16931522. Epub 2006/08/26. eng.

38. Nagel G, Peter R, Braig S, Hermann S, Rohrmann S, Linseisen J: The impact of education on risk factors and the occurrence of multimorbidity in the EPIC-Heidelberg cohort. BMC Public Health 2008, 8:384. PubMed PMID: 19014444. Pubmed Central PMCID: PMC2614432. Epub 2008/11/19. eng.

39. Wilson KC, Chen R, Taylor S, McCracken CF, Copeland JR: Socio-economic deprivation and the prevalence and prediction of depression in older community residents. The MRC-ALPHA Study. Br J Psychiatry 1999, 175:549-553. PubMed PMID: 10789352. Epub 2000/05/02. eng.

40. Espelt A, Borrell C, Palencia L, Goday A, Spadea T, Gnavi R, Font-Ribera L, Kunst AE: Socioeconomic inequalities in the incidence and prevalence of type 2 diabetes mellitus in Europe. Gaceta sanitaria/SESPAS 2013, 27(6):494-501. PubMed PMID: 23643719. Epub 2013/05/07. eng.

41. Berkman CS, Gurland BJ: The relationship among income, other socioeconomic indicators, and functional level in older persons. J Aging Health 1998, 10(1):81-98. PubMed PMID: 10182419. Epub 1998/01/07. eng.

42. Thorslund $M$, Lundberg $O$ : Health and inequalities among the oldest old. J Aging Health 1994, 6(1):51-69. PubMed PMID: 10131554. Epub 1994/01/08. eng

43. Ramsay SE, Whincup PH, Morris RW, Lennon LT, Wannamethee SG: Extent of social inequalities in disability in the elderly: results from a populationbased study of British men. Ann Epidemio/ 2008, 18(12):896-903. PubMed PMID: 19041588. Pubmed Central PMCID: 2728204. Epub 2008/12/02. eng.

44. Avendano M, Glymour MM: Stroke disparities in older Americans: is wealth a more powerful indicator of risk than income and education? Stroke 2008, 39(5):1533-1540. PubMed PMID: 18436891. Epub 2008/04/26. eng.

45. Marmot M: The influence of income on health: views of an epidemiologist. Health Aff (Millwood) 2002, 21(2):31-46. PubMed PMID: 11900185.

46. Korda RJ, Banks E, Clements MS, Young AF: Is inequity undermining Australia's 'universal' health care system? Socio-economic inequalities in the use of specialist medical and non-medical ambulatory health care. Aust N Z J Public Health 2009, 33(5):458-465. PubMed PMID: 19811484. Epub 2009/10/09. eng.

47. Korda RJ, Joshy G, Jorm LR, Butler JR, Banks E: Inequalities in bariatric surgery in Australia: findings from 49364 obese participants in a prospective cohort study. Med J Aust 2012, 197(11):631-636. PubMed PMID: 23230934. Epub 2012/12/13. eng.

48. COAG Reform Council: Healthcare 2011-12: Comparing performance across Australia. Sydney: COAG Reform Council; 2013.

49. Mackenbach JP, Meerding WJ, Kunst AE: Economic costs of health inequalities in the European Union. J Epidemiol Community Health 2011, 65(5):412-419. PubMed PMID: 21172799. Epub 2010/12/22. eng.

50. Mealing NM, Banks E, Jorm LR, Steel DG, Clements MS, Rogers KD: Investigation of relative risk estimates from studies of the same population with contrasting response rates and designs. BMC Med Res Methodol 2010, 10:26. PubMed PMID: 20356408. Epub 2010/04/02. eng.

51. Ponsonby AL, Dwyer T, Couper D: Is this finding relevant? Generalisation and epidemiology. Aust N Z J Public Health 1996, 20(1):54-56. PubMed PMID: 8799067. Epub 1996/02/01. eng.

doi:10.1186/1471-2458-14-741

Cite this article as: Korda et al:: Income-related inequalities in chronic conditions, physical functioning and psychological distress among older people in Australia: cross-sectional findings from the 45 and up study. BMC Public Health 2014 14:741.

\section{Submit your next manuscript to BioMed Central and take full advantage of:}

- Convenient online submission

- Thorough peer review

- No space constraints or color figure charges

- Immediate publication on acceptance

- Inclusion in PubMed, CAS, Scopus and Google Scholar

- Research which is freely available for redistribution 